\title{
The effect of high-pressure torsion on microstructure and strength properties of high-nitrogen austenitic steel
}

\author{
E.G. Astafurova ${ }^{1,2 \dagger}$, M.S. Tukeeva ${ }^{1}$, V.A. Moskvina ${ }^{3}$, N.K. Galchenko ${ }^{1}$, \\ I.A. Bataev ${ }^{4}$, V.A. Bataev ${ }^{4}$ \\ ${ }^{\dagger}$ elena.g.astafurova@gmail.com \\ ${ }^{1}$ Institute of Strength Physics and Materials Science SB, RAS, 2/4 Akademichesky Ave., 634055, Tomsk, Russia \\ ${ }^{2}$ National Research Tomsk State University, 36 Lenin Ave., 634050, Tomsk, Russia \\ ${ }^{3}$ National Research Tomsk Polytechnic University, 30 Lenin Ave., 634050, Tomsk, Russia \\ ${ }^{4}$ Novosibirsk State Technical University, 20 K. Marks Ave., 630073, Novosibirsk, Russia
}

In this paper, we investigate the microstructure and microhardness of high-nitrogen austenitic steel after high-pressure upset and high-pressure torsion $(6 \mathrm{GPa})$ at room temperature. As the result of deformation, steel microhardness increases by 1.5 times after high-pressure torsion per one revolution while the distribution of microhardness is quasi-homogeneous across the disks. The level of solid solution hardening of steel remains high after deformation processing, and the main mechanisms determining fragmentation of the steel structure are slip, twinning, formation of localized deformation microbands, and precipitation hardening.

Keywords: high-pressure torsion, high-nitrogen steel, twinning, particle strengthening, austenite.

The improvement of the set of physical and mechanical properties of structural steel is one of the major objectives of the modern material science, and it is traditionally achieved by using the methods of thermomechanical treatment, alloying, precipitation hardening, creating gradient structures and coatings, etc. Over the recent decades, an approach associated with the achievement of highstrength ultrafine-grained structural state in materials due to their structure refinement by severe plastic deformation (SPD) has been actively developing [1-2]. Despite the large number of studies of the effect of SPD on physical and mechanical properties of metallic materials, not many papers investigating the effect of SPD on the structure and properties of steels have been written due to the fact that there exist technological difficulties to form ultrafinegrained structures in them.

There are very few papers on SPD of austenitic steels with a high concentration of interstitial atoms as they undergo severe strain hardening as a consequence of deformation, require high pressure to achieve deformation, and can cause destruction of equipment. However, using single crystals of highmanganese austenitic steels with high carbon concentrations in papers $[3,4]$ the authors show the possibility of forming the structure comprising high density of special boundaries (twinning) under SPD. In paper [5], using austenitic steels Fe-13.4Mn-1.3C, Fe-10.1Mn-0.71C, Fe-4.3Mn-1.12C (wt.\%) with high concentrations of carbon atoms the authors formed polycrystalline structures with a crystallite sizes of $0,01-0,5 \mu \mathrm{m}$ in them using high-pressure torsion (HPT) $(6-15 \mathrm{GPa})$ at room temperature. They proved that the level of hardening of these austenitic steels is mainly determined by the content of carbon in austenite i.e. by solid solution strengthening. High-nitrogen austenitic steels (HNS) can also be used as promising materials for the development of SPD methods. Nitrogen as an alloying element is superior to other elements in terms of the austenite-forming capacity and hardening capacity, reduces stacking-fault energy and contributes to the development of mechanical twinning [6-7]. For Fe-18Cr-16Mn-0.99N austenitic steel, yield strength triples up to $1500 \mathrm{MPa}$ due to deformationinduced defects - dislocations, grain boundaries, and twin boundaries - and their interactions after HPT at room temperature [8]. Additional vanadium alloying of such steels will probably stimulate even greater strengthening effect through precipitation hardening and will allow improving thermal stability of such systems.

The aim of the paper is to establish peculiarities and mechanisms of deformation of high-nitrogen vanadiumbearing chromium-manganese austenitic steel under SPD using HPT method.

A high-nitrogen Fe-20Cr-20Mn-2.6V-0.3C-0.8N, wt.\% steel was selected as the object of investigation. The starting disks (10 $\mathrm{mm}$ in diameter and $0.7 \mathrm{~mm}$ thick) were waterquenched over an hour at $1200{ }^{\circ} \mathrm{C}$. Disk deformation was performed at a pressure of $6 \mathrm{GPa}$ using Bridgman anvils at room temperature at $N=0$ (upset without anvil revolution) and $N=1$ revolution.

For microstructural analysis, transmission electron microscopy (TEM) was performed using a Technai G2 FEI transmission electron microscope operated at $200 \mathrm{kV}$. 
The samples cut in the shape of disks with a diameter of $\approx 3 \mathrm{~mm}$ were mechanically thinned to $\approx 100 \mu \mathrm{m}$, and then electrolytic jet polishing was performed using a Tinupol-5 device in cooled electrolyte $(95 \%$ glacial acetic acid $\left(\mathrm{CH}_{3} \mathrm{COOH}\right)+5 \%$ perchloric acid $\left.\left(\mathrm{H}_{3} \mathrm{ClO}_{4}\right)\right)$ to obtain thin sites suitable for TEM analysis. Microstructural analysis after HPT was carried out in the midpoint of the radius of the disks. The average dimensions of the structure elements were measured using dark-field TEM images [9]. Microdiffraction patterns indexing was performed in a standard way, the detailed account of it is given in [9].

Vickers microhardness test was performed to measure microhardness values using a Duramin 5 microhardness tester at a load of $200 \mathrm{~g}$ on the indenter. The average microhardness value was calculated by measurements taken in the midpoint of the radius of the disk. For steel structure homogeneity analysis after HPT, microhardness values were also measured along the diameter of the samples.

The X-ray studies were performed using a Shimadzu XRD6000 diffractometer (with a monochromator). Determination of the parameters of crystalline structure - the microstrain and dimensions of coherent scattering regions - was performed using the approximation method [10].

Initially, HNS has mainly the austenitic structure with an average grain size of $100 \mu \mathrm{m}$. The lattice parameter of austenite before deformation is $0.3638 \mathrm{~nm}$, which indicates a high concentration of nitrogen and carbon atoms in the solid solution after quenching. Coupled with austenite, cubicshaped coarse particles were observed with a face $5-10 \mu \mathrm{m}$ long (optical metallography) while spherical particles with a diameter of $20-30 \mathrm{~nm}$ and of $100-150 \mathrm{~nm}$ were observed in the TEM images. The X-ray diffraction pattern reflecting the initial state of HNS also revealed reflexes different from the austenite phase with interplanar distances corresponding to particles $\mathrm{VM}(M=N, C)$ and with the lattice parameter of $0.41 \mathrm{~nm}$ (Fig.1). These particles are likely to be complex vanadium carbonitride since their lattice parameter is somewhat lower than the tabulated values for VN [11]. The X-ray lines (200) of such particles are at the angles of reflection close to the line (110) for $\alpha$-iron so that it is difficult to separate these phases. The fact that a small fraction of ferrite is still present in the structure of the steel after quenching is proved by the fact that the samples have become magnetic (only ferrite is ferromagnetic out of the possible phases [12]). The microhardness of steel in the initial state after quenching is $4.1 \mathrm{GPa}$.

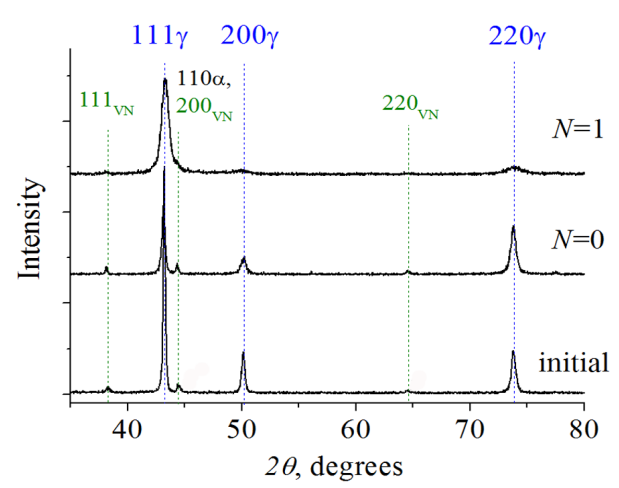

Fig. 1. X-ray diffraction patterns for HNS in the initial state, after upset $(\mathrm{N}=0)$ and torsion per revolution $(\mathrm{N}=1)$.
The upset and one-full-revolution torsion are followed by the fragmentation of the structure and line broadening in the X-ray diffraction patterns and texture formation in austenite - the predominance of $\{111\}$ planes in the plane of the anvils (Fig.1). The dimensions of coherent scattering regions become smaller with an increase in strain and amount to $\approx 70 \mathrm{~nm}$ after upset and $\approx 25 \mathrm{~nm}$ after torsion. On the contrary, crystal lattice microstrain becomes high after deformation processing and is $(2-5) \times 10^{-3}$. Regardless of the considerable line broadening in the X-ray diffraction patterns after onerevolution torsion, it is still possible to identify the reflections corresponding to particles and $\alpha$-phase in the X-ray patterns, but their lattice parameters can hardly be determined because of the broadening of the lines and their low intensity (Fig.1). After deformation, the austenite lattice parameter varies within the limit of a measurement error; this proves that the concentration of interstitial atoms (of carbon and nitrogen) in the solid solution remains unchanged at the time of torsional deformation under pressure. That is, deformation is not accompanied by nitrogen and carbon depletion of the solid solution (no formation of new particles occurs), as observed at the time of HPT of Hadfield steel in [5], and the conversion in the carbide subsystem is not accompanied by the dissolution of particles at the time of SPD in the selected modes, or both these processes compensate each other. Thus, based on the analysis of the X-ray diffraction patterns after upset and torsion, it can be concluded that the deformation processing does not cause a noticeable change in the phase composition of steel as compared to the initial state.

Steel microhardness increases with an increase in strain from $4.1 \mathrm{GPa}$ in the initial state to $5.1 \mathrm{GPa}$ after upset and to 6.2 GPa after torsion per revolution (these data correspond to the midpoint of the radius of the disks). Thus, steel microhardness increased by 1.5 times after torsion per revolution compared to the initial state. The distribution of microhardness values along the diameter of the disks for HNS depending on the treatment is shown in Fig.2. The distribution of microhardness is slightly heterogeneous after upset; a small «dip» is observed at the centre of the disks. It is associated with the peculiar properties of the sample in the state after high-pressure upset - normal stress prevails at the centre of the billet, and at the periphery, the shear of the material is added in the radial directions. After onerevolution HPT, the distribution of microhardness becomes quasi-homogeneous along the diameter of the sample, which

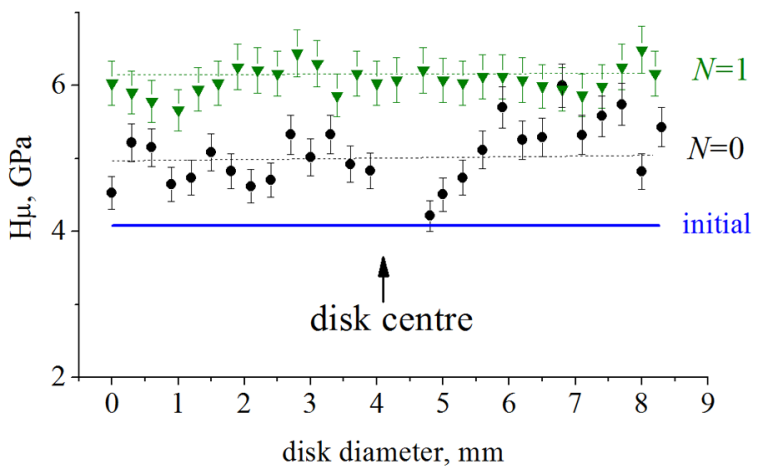

Fig. 2. Distribution of microhardness values across the disks for HNS depending on the treatment. 
is not typical of HPT deformation. In low-strength metals and alloys, torsional deformation often stimulates the formation of a heterogeneous distribution of microhardness and microstructure [2]. Such behaviour is due to the dependence of the strain from the centre to the edge of the sample $e \sim \ln r$ [2]. However, for example, in the samples of stable high-strength steels with a high concentration of carbon atoms and low stacking fault energy [4] or metastable Cr-Ni steel [13] after HPT, the authors observed homogeneous microhardness distribution that was caused by the formation of high density of twin boundaries in the structure in one case and by straininduced phase $\gamma-\alpha$ transformation in another one.

Initially high values of microhardness of HNS after quenching are, first of all, determined by solid solution strengthening and precipitation hardening. As mentioned above, the solid solution strengthening is not changed by one-revolution HPT deformation at room temperature. No significant amount of martensite with a bcc lattice was detected in the steel structure in X-ray diffraction patterns or electron microscopic studies (the midpoint of the radius of the samples). Consequently, changes in microhardness at the time of plastic deformation are caused by the accumulation of deformation defects and transformations in the carbide subsystem.

Typical TEM images of the HNS structure in the strained conditions are shown in Fig.3. High density of dislocations, localized deformation microbands (about $100 \mathrm{~nm}$ wide), and twins (Fig.3a,b) with the plates dozens of nanometers thick is observed after upset and torsion in the steel structure. With an increase in strain, the number of localized bands increases.

The dislocation density cannot be estimated by TEM; however, according to the estimations based on the analysis of line broadening in the X-ray diffraction patterns [14], it was $8 \times 10^{12} \mathrm{~m}^{-2}$ after upset and $4 \times 10^{13} \mathrm{~m}^{-2}$ after torsion per one revolution. That is, the accumulation of dislocations is one of the reasons for the increase in steel microhardness with an increase in strain.

No formation of well-developed grain/subgrain structure typical of alloys and steels deformed using the HPT method $[1,2,13]$ is observed after the chosen deformation processing methods. Microdiffraction patterns for structural regions that contain high density of twin boundaries contain almost not diffused point reflections arising from the matrix, twins, double reflections and bands due to the formation of thin twin plates. In addition to twinning, reflections, interplanar distances of which correspond to $\varepsilon$-martensite, were observed in such regions. In the regions with prevailing localized deformation bands (Fig.3c), microstrain images indicated the formation of misoriented structure with continuous and discrete misorientations (the area of the regions, of which microdiffraction images were taken, is $0.95 \mu \mathrm{m}^{2}$ ). However, the azimuthal diffusion of austenite reflections reaches 20 degrees after torsion per full revolution. In addition to the reflections of austenite and $\mathcal{\varepsilon}$-martensite, one observed point microdiffraction patterns of vanadium particles $100-150 \mathrm{~nm}$ each. A contrast of fine particles $<10 \mathrm{~nm}$ in the body of grains were also detected in dark-field images after torsion per revolution (the contrast was not detected after upset), which also can give a significant contribution to steel strengthening.
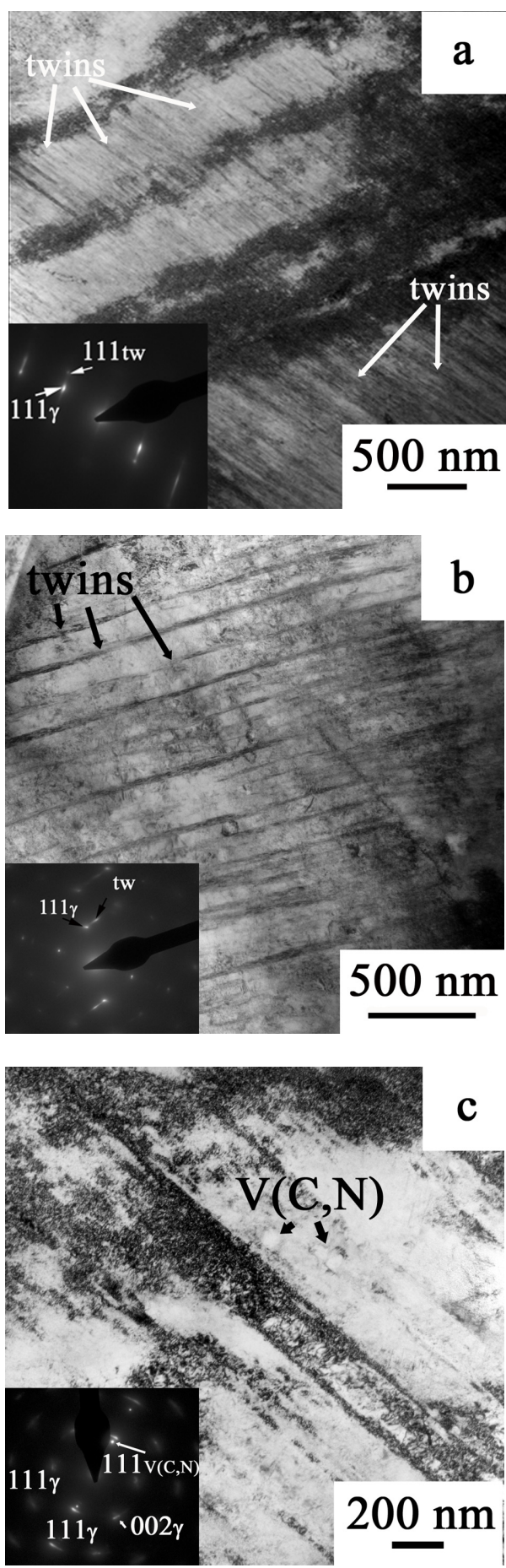

Fig. 3. TEM images of the structure of HNS after upset (a) and torsion per revolution $(b, c)$. Microdiffraction patterns were obtained from the regions of $0.95 \mu \mathrm{m}^{2}$ in area. $t w$ - twin reflections.

Thus, high microhardness values of the samples after HPT per revolution are determined by the active development of mechanical twinning, the formation of localized deformation bands, the accumulation of dislocations, and precipitation hardening while maintaining a high level of solid-solution hardening. High concentration of nitrogen in the solid solution contributes to the development of mechanical twinning and structure stability to the $\gamma$ - $\alpha$ - transformation.

Based on the analysis of the data on strain hardening of HNS at the time of upset and HPT (6 GPa) at room temperature, the following conclusions can be made: 
- As the result of deformation, steel microhardness increases from initial 4.1 GPa to 5.1 GPa after upset and to 6.2 GPa after HPT per one revolution (in the midpoint of the radius of the disks). The distribution of microhardness across the disks is quasi-homogeneous after plastic deformation while the homogeneity values increase with an increase in strain.

- The level of solid-solution strengthening of steel remains high after deformation processing; the major mechanisms that determine structure fragmentation and strain hardening of steel are slip, twinning, formation of localized deformation bands, and precipitation hardening. Active development of mechanical twinning facilitates strain hardening due to high density of high-angle special (twin) boundaries and prevents the formation of well-developed misoriented grain/subgrain structure with common type boundaries and, thus, contributes to the homogeneity of the structure and microhardness across the sample.

This research was conducted using the equipment provided by Tomsk Materials Science Centre of Tomsk State University and was partially supported by Russian President Scholarship (SP-4384.2013.1).

\section{References}

1. R.Z. Valiev, R. K. Islamgaliev, I. V. Alexandrov. Prog. Mater. Sci. 45, 103 (2000).

2. A.P. Zhilyaev, T. G. Langdon. Prog. Mater. Sci. 53, 893
(2008).

3. E.G. Astafurova, M.S. Tukeeva, G.G. Zakharova, E. V. Melnikov, H. J. Maier. Mater. Char. 62, 588 (2011).

4. E.G. Astafurova, M.S. Tukeeva, G.G. Maier, E. V. Melnikov, H.J. Maier. Mater. Sci.Eng. A604, 166 (2014).

5. V.A. Teplov, L.G. Korshunov, V.A. Shabashov, R.I. Kuznetsov, V.P. Pilyugin, D.I. Tupitsa. Phys. Met. Metall. 66, 563 (1988). (in Russian)

6. V. Gavriljuk, H. Berns. High nitrogen steels. New York, Springer-Verlag Berlin Heidelberg. (1999) 378 p.

7. T.-H. Lee, C.-S. Oh, S.-J. Kim, S. Takaki. Acta Mater. 55, 3649 (2007).

8. F. Y.Dong,P.Zhang,J. C.Pang, Y. B.Ren,K. Yang,Z. F.Zhang. Scripta Mater. (2014), http://dx.doi.org/10.1016/j. scriptamat.2014.09.016 (in press)

9. D.B. Williams, C.B. Carter. Transmission Electron Microscopy. New York, Springer. (2009) 760 p.

10. S.S. Gorelic, Yu.A. Skakov, L. N. Rastorguev. X-ray diffraction and electron-optical analysis. Moscow, MISIS. (2002) 360 p. (in Russian)

11. O.A. Bannykh, V.M. Blinov. Precipitation hardening nonmagnetic vanadic steels. Moscow, Nauka. (1980) 190 p. (in Russian)

12. K. Mumtaz, S. Takahashi, J. Echigova, Y. Kamada, L. F. Zhang, H. Kikuchi, K. Ara, M. Sato. J. Mater. Sci. 39, 85 (2004).

13. A. A. Zakirova, E. I. Sadikova. Letters on Materials. 2(4), 235 (2012). (in Russian)

14. G. K. Williamson, R. E. Smallman. Phil. Mag. 1, 34 (1956). 